\title{
Los mapas de Andalucía, noticias antiguas del territorio. Reconocimiento y evaluación de los archivos cartográficos con información sobre Andalucía
}

Joaquin Cortés José, Instituto de Cartografia de Andalucia

La cartoteca del Instituto de Cartografía de Andalucia es un proyecto que pretende conocer, localizar, describir, reproducir y difundir todos los mapas, planos y vistas que se conservan sobre el territorio y las ciudades andaluzas. El documento cartográfico nos informa sobre el territorio desde hace, al menos, quinientos años: de sus elementos físicos, estructura, red de vias de comunicación, ciudades, etc

El mapa se presenta en distintos formatos, de los que distinguiremos el impreso del manuscrito. Este último es el documento cartográfico de archivo por excelencia, vinculado generalmente a un expediente que forma parte de una serie de un fondo producido por un organismo o entidad. El documento cartográfico archivístico es menos conocido y está menos estudiado desde el punto de vista de la historia de la Cartografía. El mapa impreso, suelto o encuadernado formado un atlas, es un producto editorial con un propósito divulgativo.

El análisis del origen, procedencia, o el proceso de creación de los fondos cartográficos nos aporta una información complementaria. Hay algunos que disponen de una documentación más o menos homogéna, se formaron por proyectos cartográficos propiamente dichos, como el Mapa Topográfico Nacional 1:50.000; otros responden a proyectos que se apoyan en la cartografía (carreteras, ferrocarriles, etc.)

La cartografía catalogada en el Instituto de Cartografía de Andalucía procede de más de 1.000 bibliotecas y archivos que custodian y conservan un amplio y rico patrimonio documental que nos ha permitido recuperar la información antigua del territorio, pero no debemos olvidar las cartotecas del futuro que preservarán la información y la cartografía que se produce hoy.

\section{Palabras clave}

Andalucia / Archivos / Bibliotecas / Cartografías / Cartografía histórica / Cartotecas / Historia / ICA Instituto de Cartografía de Andalucia / Mapas / Metodología / Planos / Vistas de ciudades / Vistas del territorio

\section{INTRODUCCIÓN}

"Los mapas son un instrumento para aprender a leer y descifrar el territorio, ya que el territorio no es simplemente lo que vemos; mucho más que montañas, ríos, valles, asentamientos humanos, puentes, caminos, cultivos, paisajes, es el espacio habitado por la memoria y la experiencia de los pueblos" (RESTREPO BOTERO; VELASCO ÁLVAREZ; PRECIADO BUITRAGO, 1999).

El mapa, como cualquier otro documento, tiene un valor administrativo, fiscal, informativo, histórico y cultural. Cuando extendemos un mapa antiguo nos habla e informa del pasado del territorio $y_{1}$ adiestrándonos en su lectura, en muchos casos nos sorprenderá. La cartografía de Andalucía informa del territorio, soporte de las actividades productivas y base del desarrollo socioeconómico y cultural de la sociedad. Pero, como toda noticia, es necesario caracterizarla, conocer su fuente, cómo se ha construido y contrastarla con otros mapas. Se dispone de un volumen importante de cartografía antigua con más de cinco siglos de historia, de amplia variedad temática y diversidad de datos cuya singularidad o redundancia nos matiza la información antigua del territorio de Andalucía.

\section{LA CARTOTECA HISTÓRICA DEL INSTITUTO DE CARTOGRAFÍA DE ANDALUCÍA}

El Instituto de Cartografía de Andalucía dispone entre sus fondos de una colección micrográfica-digital de mapas, planos y vistas del territorio y de las ciudades de Andalucia que se ha formado con el propósito de conocer y divulgar toda la documentación gráfica antigua que se está localizando sobre la Comunidad Autónoma. A una primera fase metodológica, donde se definió pormenorizadamente la estrategia de búsqueda, las normas de catalogación y la técnica de reproducción, siguió la fase de catalogación, en la que, en los dos primeros años de trabajo, se superaron todas las previsiones que se habian hecho en cuanto al número de mapas. Desde entonces ha sido una sorpresa tras otra, ya no tanto por el volumen, sino por el rico patrimonio documental y por la amplia diversidad temática. 
El proyecto nunca ha perdido la perspectiva de ver los mapas y planos como fuente de información para el estudio del territorio y el urbanismo y no como un objeto de valor, de colección o para incrementar el acervo cultural y patrimonial. Asi pues, desde la descripción catalográfica, generalmente con abundantes notas sobre su contenido, el sistema de recuperación de la información, con múltiples puntos de acceso, o la "masiva" difusión de este proyecto, en voluminosos catálogos impresos, en la web o en los más recientes catálogos digitales, siempre ha pretendido facilitar el acceso al mapa en función al dato o a la información que contiene.

Junto al valor informativo y a los datos que aporta para el conocimiento de la historia de Andalucia, el documento cartográfico presenta dos facetas más o dimensiones. Una en cuanto a su expresión artística, centrada en la representación del territorio y el paisaje, las cartelas, ilustraciones y otros elementos decorativos del mapa en los que se emplean diversas técnicas (lápiz, carboncillo, tinta, aguada, pastel, óleo, textil, xilografía, calcografía, litografía, maquetación...); y otra relativa a sus aspectos científico-técnicos, información intrínseca a su construcción que se concreta en su representación geométrica, cuya precisión depende de las técnicas de posicionamiento (topografía), de la medición de la Tierra (geodésica) y, en definitiva, de la evolución de la Cartografía. Otros autores (HARLEY, 2005) le añaden otras dimensiones, como su valor simbólico, utilizado consciente (en la mayor parte de los casos) o inconscientemente (que se duda de la existencia de algún caso), mediante el que se selecciona o manipulan las anteriores para obtener un resultado favorable al promotor del mapa o a la autoridad propietaria. En estas lineas no nos vamos a ocupar de dicho valor, ni de la evolución de las técnicas de posicionamiento, para centrarnos en el valor de la información representada, de su diversidad temática y de los archivos y bibliotecas donde se encuentran los mapas de Andalucia.

\section{LA RECOPILACIÓN}

El criterio seguido en los trabajos de inventario-catalogación ha sido ir de los archivos más antiguos a los más modernos, de los organismos productores a los usuarios de cartografía, de los archivos y bibliotecas estatales a los dependientes de la administración autónoma. Fuera de esta secuencia hemos entrado en bibliotecas y archivos privados (Cádiz, Córdoba y Huelva) y en los dos grandes archivos nobiliarios de Andalucia (Medina Sidonia y Medinaceli). Estos criterios nos permitirían conocer los mapas más antiguos del territorio de Andalucia e identificar las posibles relaciones con sus antecesores, identificar ejemplares duplicados, etc. En trabajos posteriores, nos ha permitido conocer a sus autores, hacer un seguimiento a su actividad profesional, si llegaron a formar sagas familiares, su especialización, etc.; del mismo modo, preguntar por sus promotores o por los temas que necesitaban realizar y apoyarse en la cartografia.

Los criterios de selección que se han seguido han sido varios. Por un lado, el límite cronológico, que se estableció inicialmente en la década de los 60 del siglo pasado pero actualmente se ha superado y se catalogan mapas hasta los años 80 . En cuanto al contenido de los mapas, no se ha discriminado ninguna temática, comprobándose que, con el paso del tiempo, se ha ampliado y diversificado; pero hay temas que actualmente son habituales en la cartografía y que no se han incorporado a los mapas hasta hace relativamente poco tiempo, así los primeros mapas geológicos o los estadísticos aparecen en la primera mitad del siglo XIX. La escala de los mapas se fijó como límite superior en 1:500, no obstante se ha catalogado cualquier mapa de escala superior siempre que tuviera una mínima representación territorial, como por ejemplo un plano urbano de Sevilla a escala 1.300 del ingeniero Ignacio Beyens (ca. 1921) o diversos planos de líneas de distintas ciudades andaluzas que son incluso de escalas superiores.

\section{LOS MAPAS DE ARCHIVO Y LOS MAPAS DE BIBLIOTECA}

La cartografía antigua se presenta fundamentalmente impresa o manuscrita. La primera la solemos encontrar en las bibliotecas, como atlas o mapas sueltos; son productos editoriales cuya mayor o menor difusión dependía de si la edición estaba dirigida al "gran público" de la época o a sectores más selectos amantes de ediciones de alta calidad. Así, por ejemplo, durante el periodo de los siglos XVI, XVII y primera mitad del XVIII, hubo ediciones hechas en exclusiva o "a medida", en las que el cliente seleccionaba los mapas que formarían el atlas (ediciones del Atlas de J. Blaeu). Todo esto explica, en parte, que unos mapas sean más conocidos que otros, que se encuentren con más facilidad en las bibliotecas o sean más raros.

El plano manuscrito es el documento cartográfico por excelencia de los archivos, pero no exclusivo, porque también se pueden encontrar en las secciones de manuscritos en algunas bibliotecas. La génesis del mapa de archivo es muy diferente del impreso; suele estar vinculado a un expediente que forma parte de una serie de un fondo producido por un organismo o entidad productora. El documento archivístico es mucho más abundante, menos conocido y está menos estudiado desde el punto de vista de la historia de la cartografía. En este tipo de mapas es necesario hacer una clara distinción entre los que responden a proyectos de organismos productores de cartografía de los que no lo son; en estos últimos el documento cartográfico no tiene fines científicos, sino administrativos o de gestión, tiene plenamente un carácter práctico y prosaico, y comparte la unicidad y singularidad con el resto de las piezas de archivo.

En cambio, los mapas impresos son generalmente más conocidos en el mundo de la cartografía, se encuentran citados en numerosas obras de referencia, se conocen a sus autores, editores/impresores, el número de ejemplares de sus tiradas, los estados, etc. El contenido de los mapas impresos varia en función de su promotor y hay que distinguir entre la iniciativa pública y la privada. Los primeros mapas impresos en Europa datan del siglo XV (los mapas impresos más an- 
tiguos proceden de China, grabados por Liu Ching Zu, 1155); a partir de la segunda mitad del siglo XVI comienza la edición impresa de atlas y aumenta el número de editores europeos.

La cartografía institucional promovida por los Estados no aparece hasta el siglo XVIII, aunque podamos encontrar algún mapa nacional a finales del siglo XVII y algunos proyectos que no se llevaron a cabo. Las cartas nacionales promovidas por las monarquias ilustradas deben tener corrección geométrica (mapa geométrico...), normalización de contenidos y clave homogénea de signos convencionales. Con la cartografía oficial de los países no desaparece la iniciativa privada que seguirá imprimiendo mapas sueltos o atlas por demanda, aunque en muchos ejemplares se aprecia la influencia de la institucionalización de la Cartografía. En la segunda mitad del siglo XIX se editan los primeros atlas modernos, en los que, junto a los mapas de todos los continentes, aparecen secciones del firmamento, del sistema solar, de la estructura de la tierra, secciones históricas del pais donde se edita, secciones de estadisticas, etc.

\section{EL ORIGEN DE LOS FONDOS CARTOGRÁFICOS}

Los especialistas definen archivo como una colección de documentos reunidos por una entidad en el ejercicio de una actividad práctica o necesaria (ROMERO TALLAFIGO, 1994). Continúan diciéndonos que dicha reunión es impuesta por ley, ordenanza o necesidad de la entidad que la produce y que esta necesidad hace que los documentos se reúnan seriada, continua y organizadamente porque la función archivistica está, como las actuaciones que la originan, normalmente reglada. Por lo tanto el conocer el origen de los fondos nos informa y caracteriza la documentación cartográfica que contiene.

Las bibliotecas no tienen la estructura orgánica de los archivos pero, en ciertos casos, no es menos interesante detenerse a conocer su procedencia y génesis, que nos aportan una información complementaria. Asi, muchas de las bibliotecas públicas más antiguas (las de las universidades) cuentan con un fondo antiguo que se ha ido formando no sólo por un plan de compras propio o por adquisición de bibliotecas privadas, sino también por donaciones de distintas instituciones que las formaron como respuesta a la búsqueda de un conocimiento, ciencia, temática o interés distinto en cada una de ellas y que caracteriza a sus antiguos propietarios y a una época. Esto explica que algunas bibliotecas sean más ricas en obras de Cartografía (atlas, tratados de Cartografia, Astronomía, Matemáticas...) o con cartografía (libros de Geografía, exploraciones geográficas, libro de viajes...) que en otras, y que alguna de estas colecciones tengan un escaso número de ejemplares y otras sean muy completas.

Las bibliotecas, cuando disponen de un cierto volumen de mapas sueltos, forman una colección y los organizan en la sección de mapas y planos; los archivos, ante la misma situación, o porque se vean obligados por necesidades de conservación a sacarlos de los legajos, forman las denominadas colecciones (ya no secciones) facticias de mapas, planos y dibujos (no derivadas de un organismo administrativo productor). Los organismos productores de cartografía organizan sus fondos cartográficos (documentación de apoyo, minutas, manuscritos e impresos) en el archivo cartográfico o cartoteca.

\section{LA INFORMACIÓN}

La información obtenida en los más de 1.000 archivos y bibliotecas visitados, que suma algo más de 140.000 mapas catalogados, está descrita con más de 950 términos de materia, lo que supone una amplia diversidad temática. Tal como se ha dicho, sólo de cartografía impresa, tanto atlas como mapas sueltos, se han encontrado ejemplares en distintas bibliotecas ${ }^{1}$. El documento de archivo es único, aunque pueden existir copias realizadas por distintas técnicas y que se referencian como tales. Por esta razón con frecuencia se ha encontrado un proyecto original en un archivo central y la copia en el archivo de la delegación provincial. Esta circunstancia ha permitido a veces completar un proyecto desmembrado, o, por el contrario, diferenciarlos por las modificaciones que incorpora alguno de ellos (carreteras, ferrocarriles, puertos, proyectos de regadío, etc.).

La historia de la cartografía española nos habla de proyectos cartográficos que se han ido llevando a cabo con distinto grado de ejecución, pero hay otros muchos que, sin ser cartográficos, produjeron un volumen importante de mapas de una amplia cobertura y que aportan información territorial y urbana a un nivel de detalle que supera al de los mapas nacionales. Son los proyectos ferroviarios, carreteras, minas, catastrales, etc.

A lo largo de la historia de la Cartografía los proyectos más antiguos conocidos para levantar mapas del mundo son los de Ptolomeo, Al-Idrisi o el Atlas Catalán de A. Cresques. A partir de la Edad Moderna, surgen proyectos nacionales para levantar mapas de España: Atlas de El Escorial, en el siglo XVl; el Atlas de Pedro Texeira, en el siglo XVII; el Mapa de los Jesuitas, la obra de Tomás López y el Atlas Marítimo de España de Vicente Tofiño (de la Dirección de Trabajos Hidrográficos), en el siglo XVIII; el Estado Mayor del Ejército, Francisco Coello, la Comisión del Mapa Geológico de España (del Instituto Geológico y Minero), Mapa Topográfico Nacional (del Instituto Geográfico Nacional), en el siglo XIX; y por último en el siglo $X X$, el Mapa Nacional Topográfico Parcelario (del Instituto Geográfico Nacional), el Mapa Topográfico Nacional 1:25.000, Catastro de Urbana y, finalmente, proyectos cartográficos de las Comunidades Autónomas; en el caso de Andalucía, el Mapa Topográfico 1:10.000.

Entre los otros proyectos, se encuentran los relativos a recursos forestales, defensa de costas, colonización de Sierra Morena (siglo XVIII) y proyectos hidráulicos, de minería, líneas ferroviarias, proyectos portuarios y de carreteras (siglos XIX y XX), de regadio del Instituto Nacional de Colonización (siglo XX), proyectos de abastecimiento de agua y redes de saneamiento de los municipios y ciudades andaluzas (finales del siglo XIX y primera mitad del XX) o los primeros planes urbanisticos. 


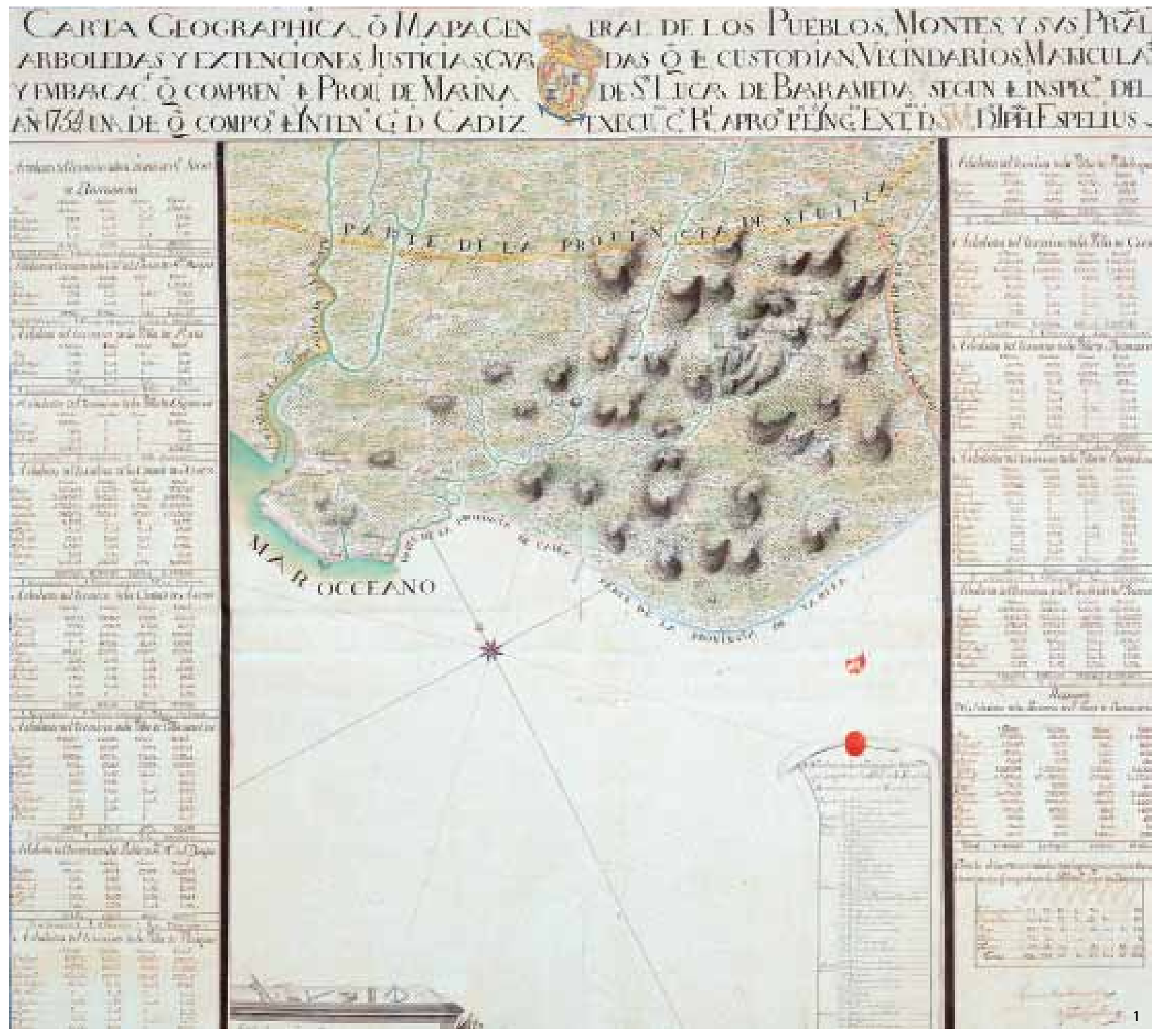

1. Sanlúcar de Barrameda (Cádiz) / Dn. Jph. Espelius. 1754. Fuente: Ministerio de Educación, Cultura y Deporte. Biblioteca Nacional-M. XLIII/348

De los proyectos nacionales enumerados, sólo ocho llegaron a imprimir sus series cartográficas o, al menos, parte de los mapas elaborados; en cambio, prácticamente de todos se conserva las minutas, la cartografía manuscrita que fue necesaria para levantarla, e incluso la documentación escrita con descripciones del territorio, observaciones astronómicas, rutas de brújula, nivelaciones, etc. Los restantes proyectos son documentación de archivo, donde el mapa aparece vinculado orgánicamente a su expediente que complementa su información. No obstante, los avatares que han podido sufrir los archivos (como los de las empresas mineras), en algunos casos, han fragmentado la documentación y se han encontrado planos sin referencia al expediente o expedientes que han perdido sus planos.

\section{APORTACIÓN DE LA CARTOTECA DEL INSTITUTO DE CARTOGRAFÍA DE ANDALUCÍA}

La información que dispone la cartoteca del Instituto de Cartografía de Andalucia pretende ser un sistema de referencia sobre la cartografía de Andalucia. No es un catálogo colectivo, en ningún momento supera los inventarios o catálogos de los archivos y bibliotecas, respectivamente, porque sólo se ha seleccionado la cartografía de nuestro interés, y tiene vocación de integrase en otros sistemas documentales y de información geográfica junto al resto de la información territorial de Andalucía.

\section{Las bibliotecas y archivos andaluces}

La recopilación de la cartografía histórica de Andalucia de los archivos andaluces tuvo la oportunidad de iniciarse cuando el proyecto de inventario de los archivos llevaba un importante camino recorrido, lo que nos permitió conocer y ampliar notablemente el repertorio de los fondos cartográficos conservados en Andalucia. Las Diputaciones Provinciales se responsabilizaron del inventario de los archivos de la administración local, por lo que contamos con su colaboración y experiencia, y pudimos acceder a los archivos municipales con una documentación que hasta ese momento, en muchos casos, se encontraba sin organizar, sin personal técnico 

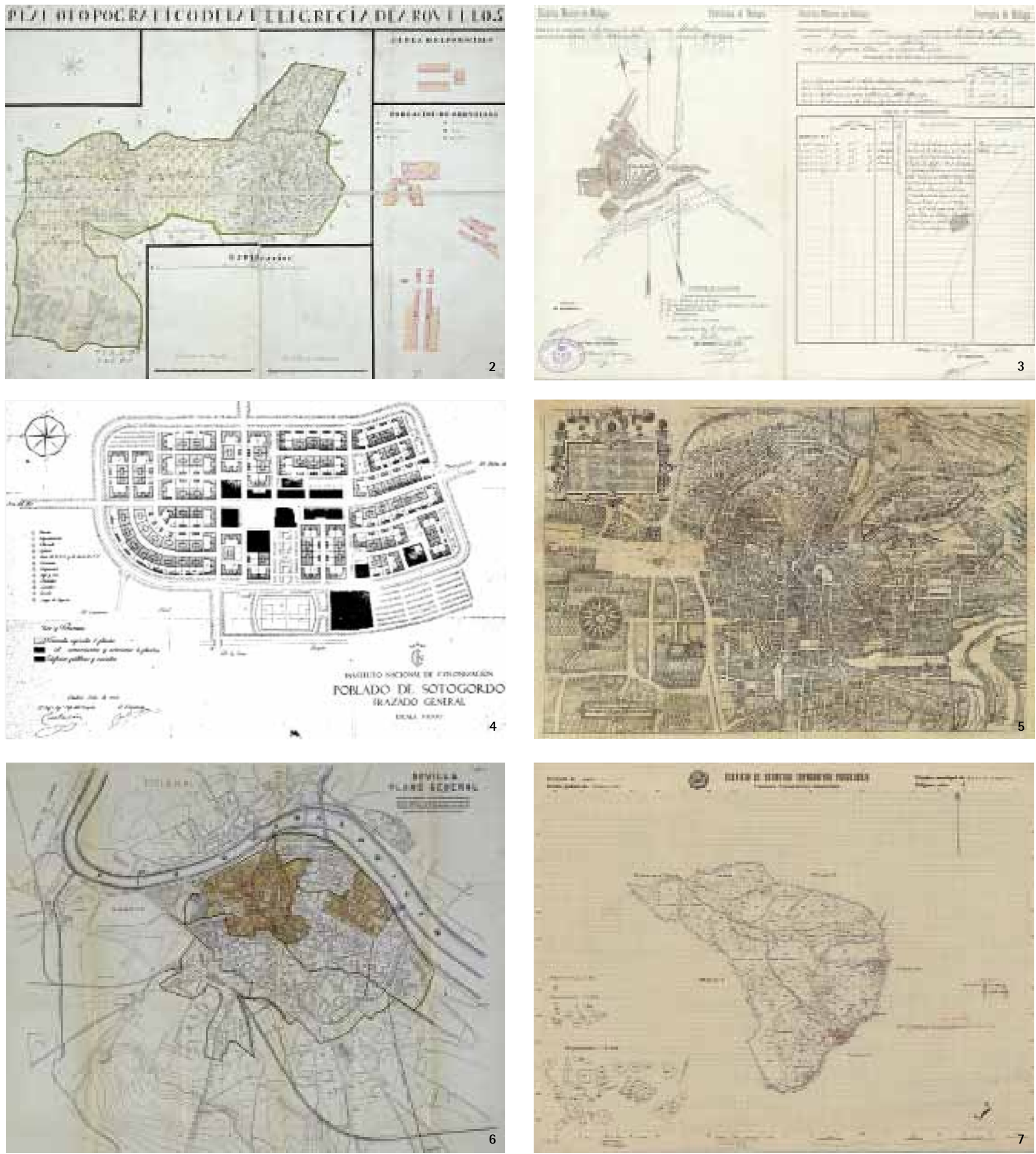

\section{El Mediterráneo era más largo:} hasta el siglo XVII los portulanos de las escuelas europeas presentaban un alargamiento del Mediterráneo en $20^{\circ}$ (de $42^{\circ}$ a $62^{\circ}$ ), dicho alargamiento le afectó proporcionalmente a los primeros mapas de Andalucía. A finales del siglo XVI Mercator lo corrigió parcialmente en $10^{\circ}$ menos
2. Arquillos (Jaén) / Joseph de Ampudia y Valdés. 1794. Fuente: Centro Geográfico del Ejército $\mathrm{n}$ ․ 102

3. Málaga (Municipio) / Distrito Minero de Málaga; El Jefe del Distrito, Alberto Herrera; El Ingeniero, J. Benjumea. 1904. Fuente: Archivo Histórico Provincial de Málaga. Fondo de Minas. Legajo 8923. Expediente 3686

4. Poblado de Sotogordo (Palma del Río, Córdoba) / Instituto Nacional de Colonización; el ingeniero agrónomo Castañón; el arquitecto Manuel Jiménez Varea. Fuente: IRYDA (Instituto para la Reforma y el Desarrollo Agrario) n. 159, pl. 13 5. Granada / Ambrosio de Vico Maestro Mayor de la insigne Iglesia de Granada; Francisco Heylan Fecit. 1595-1613. Fuente: Archivo Histórico Municipal de Granada, N.․ reg.: 1 / Sig. 005.001.00

6. Sevilla. 1902. En: Saneamiento de poblaciones españolas. Sevilla / Ángel Pulido Fernández. Madrid, 1902. Fuente: Instituto de Cartografía Andalucía 7. Beas de Segura (Jaén). Polígono n. 8 / Demetrio Quirós [Bonet]; Juan Sendra; Instituto Geográfico y Catastral. 1942. Fuente: Archivo Histórico Provincial de Jaén, signatura 48055 
especializado o carente de preparación, y en "depósitos" inadecuados para su custodia y conservación.

No obstante, el mal estado en que se han encontrado algunos mapas ha estado relacionado con las caracteristicas físicas del documento cartográfico (sus dimensiones, tipo de material, etc.) que han dificultado su almacenamiento, por lo que en muchos casos han acabado en los lugares menos accesibles y más inadecuados para su conservación. Hay que señalar que la labor que se ha hecho para la localización, catalogación y reproducción de los mapas en los archivos municipales ha contribuido en gran manera a su puesta en valor $y$, en consecuencia, se ha colaborado de algún modo a mejorar su preservación. Esta colaboración se ha mantenido a lo largo de estos años y desde entonces muchos archivos municipales siguen en contacto con la cartoteca compartiendo información y experiencias.

Los archivos históricos municipales de las capitales andaluzas se encontraban mejor dotados de personal y medios lo que facilitó en gran medida el acceso a su documentación. En todos se custodia el plano más antiguo de la ciudad (manuscrito o impreso): Granada (1595-1613), Almería (ca. 1704-1710), Sevilla (1771), Málaga (1790), Cádiz (ca. 1810), Córdoba (1811), Huelva y Jaén (segunda mitad del siglo XIX).

Los archivos históricos provinciales no cesan de incrementar sus fondos, continúan realizando una incansable labor para localizar, recuperar e incorporar los fondos documentales de su competencia, entre los que se encuentran los archivos de las antiguas delegaciones o unidades provinciales de la administración central (catastro, obras públicas, concesiones mineras, agricultura, etc.), por lo que en varios casos se han iniciado nuevas fases de catalogación de los nuevos fondos incorporados. Entre los fondos con más cartografía se encuentran los del catastro, desde los trabajos agronómicos de finales del XIX a los avances catastrales de las primeras décadas del siglo $X X_{1}$ o la documentación y las hojas del Mapa Nacional Topográfico Parcelario. Los casos de los archivos históricos provinciales de Córdoba, Jaén, Granada y Almeria conservan también la interesante documentación gráfica que se encuentra en las Respuestas Generales del Catastro de Ensenada de la segunda mitad del siglo XVIII.

Se ha catalogado cartografía en los archivos de las catedrales de Cádiz, Córdoba, Jaén y Sevilla con numerosa documentación de las posesiones eclesiásticas en las correspondientes provincias. Como se ha mencionado, los archivos nobiliarios catalogados son el de la Casa de Medina Sidonia y el Archivo Ducal de Medinaceli. El primero conserva la documentación más antigua sobre Andalucia (siglo XIII); no obstante, en lo que lo que se refiere a mapas, planos o croquis, se equipara al Archivo General de Simancas (siglo XVI).

Entre los archivos privados, hay que destacar los de las empresas mineras que durante los siglos XIX y XX extrajeron del subsuelo los recursos minerales. Este tipo de documentación se ha catalogado en las cuencas mineras de Huelva, Sevilla y Córdoba, donde cabe destacar la labor de la Fundación Río Tinto, que ha realizado un notable esfuerzo por recuperar archivos de empresas mineras, que en algunos casos habían sido vendidos al peso como papel viejo. En sus fondos se encuentra una parte importante de la historia económica de la provincia de Huelva.

Los archivos de las autoridades portuarias disponen de una documentación que generalmente data del último tercio del siglo XIX cuando se crean las Juntas de Obras del Puerto (EI Decreto de 25 de noviembre de 1870 autorizó la creación de las juntas de Almería -1879-, Cádiz -1874-, Huelva -1873-, Málaga -1873- y Sevilla -1872-). La cartografía portuaria se centra en el puerto, sus instalaciones, accesos de los sistemas terrestres de transportes (carreteras y ferrocarril) y la transformación urbana de su entorno. Por último, citar que se han catalogado colecciones particulares de cartografía, una en Huelva, dos en Cádiz y una en Jerez, entre las que hay que destacar por su volumen la colección de mapas que formaba parte de la biblioteca de Federico Joly actualmente depositada en el Museo de Cádiz.

Las bibliotecas de Andalucia disponen entre sus fondos de una importante colección de atlas donde podemos encontrar ejemplares de las primeras ediciones de las obras de Ptolomeo, de Abraham Ortelius (Teatrum orbis terretum), de George Braun (Civitates Orbis Terrarum), ludoci Hondij y Gerardis Mercatoris (Atlas sive cosmographicae meditationes de fabrica mundi et fabricati figura) o Joannes Blaeu (Atlas Maior). 0 los atlas maritimos de Robert Dudley (Dell'Arcano del mare) (Los Secretos del Mar) (1646) o el de la Dirección de Hidrografía de la Marina (Atlas maritimo de España), llevado a cabo bajo la dirección del Brigadier de la Real Armada Don Vicente Tofiño de San Miguel. Las bibliotecas universitarias como las de Granada y Sevilla tienen en sus fondos antiguos varios incunables y numerosas obras del XVI, XVII, XVIII y XIX. La Universidad de Granada tiene además tres manuscritos singulares, tres cartas portulanas sobre vitela, atribuidos Francesc Oliva (ca. 1660): una del Mar Mediterráneo, una de la costa atlántica de Europa y norte de África y una del Mar Egeo. La biblioteca de la Universidad de Sevilla realizó a lo largo de 2008 y 2009 una fase importante de digitalización y catalogación de los mapas contenidos en los atlas, libros de viajeros, libros de exploraciones geográficas, etc. y un estudio de dicho material por diferentes especialistas que arrojó resultados de notable interés sobre el fondo antiguo y sus obras de cartografía o con cartografía (POSADA SIMEÓN; PEÑALVER GÓMEZ, 2010).

Entre las bibliotecas públicas provinciales que se han catalogado cabe destacar la de Córdoba, con obras de Ptolomeo y atlas del siglo $X I X$. Otras bibliotecas nos han sorprendido al contar entre sus fondos con algunos atlas antiguos del siglo XVII, XVIII y XIX, por custodiar fondos procedentes de bibliotecas de particulares o instituciones desaparecidas, como el caso concreto del Instituto de Secundaria Séneca de Córdoba. También se han catalogado algunas bibliotecas privadas, entre las que cabe destacar la de la Institución Colombina, 


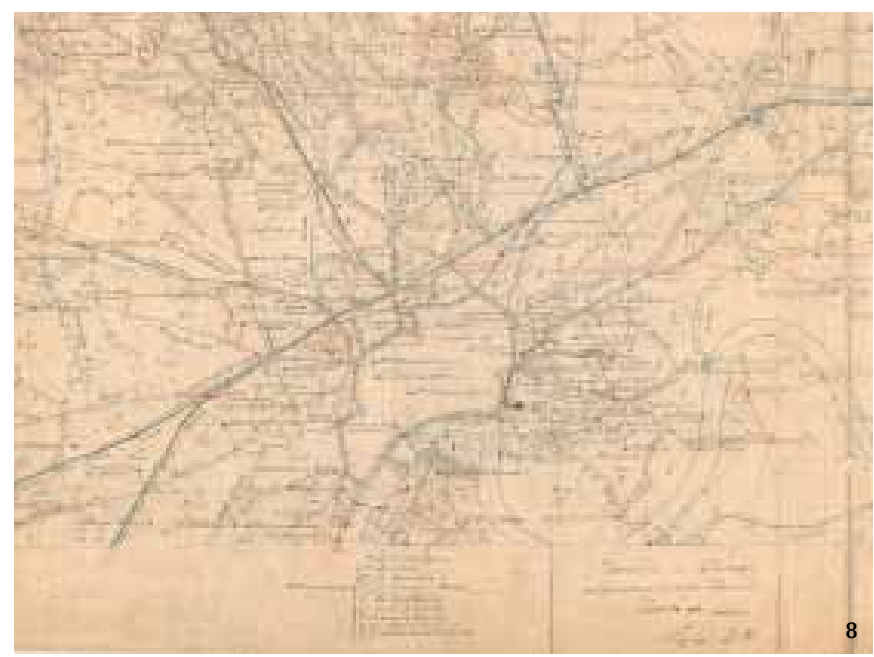

8. Detalle de la planimetría del término municipal de Córdoba. Hoja B2. Enrique Partagás... [et ál.]. 1872. Fuente: Instituto Geográfico Nacional, ref. 140071

testimonio y símbolo científico e intelectual de una época (s. XVI) y de su propietario, el erudito Hernando Colón.

Dentro de la labor de recuperar, enriquecer los fondos de originales y difundir la cartografía histórica, hay que destacar la Biblioteca de Andalucia y la biblioteca del Instituto de Estudios Giennenses (Diputación de Jaén). La primera dispone de más de 300 mapas que ha publicado en un catálogo digital en 1998 (COLECCIÓN, 1998). El Instituto de Estudios Giennenes ha publicado un catálogo de su fondo cartográfico de 1.250 mapas de Andalucia y del resto de España y de Europa (CONTRERAS GILA, 2008), y una carpeta de planos con una selección de 6 mapas provinciales de Jaén (CONTRERAS GILA; LÓPEZ CORDERO, 2008).

\section{Las bibliotecas y archivos nacionales}

Las colecciones de mapas de los archivos nacionales (Simancas, Histórico Nacional o General de Indias) son más conocidas y difundidas porque disponen de catálogo y actualmente están en proceso de digitalización (Simancas e Indias concluidos). No obstante todavía se espera que se incrementen sus colecciones, con nuevos mapas contenidos en el interior de legajos que no se han abierto o no han sido consultados. Un caso especial es el Archivo General de la Administración, donde los más de 15.000 mapas catalogados sobre ferrocarriles, tranvías, carreteras y puertos se encuentran insertos en sus legajos lo que ha impedido reproducirlos, junto al volumen de mapas y la falta de medios y personal para los trabajos de digitalización.

La Biblioteca Nacional (fundada en 1711) tiene una colección muy importante de mapas impresos y manuscritos. Los primeros proceden sobre todo por un privilegio real, precedente del actual depósito legal, por el que los impresores debian depositar un ejemplar de los libros impresos en España ${ }^{2}$. El fondo inicial de la colección cartográfica está formado por los fondos fundacionales procedentes de la Biblioteca Real, los que Felipe $\mathrm{V}$ trajo de Francia y los que por diferentes vías ingresaron en la Biblioteca formando colecciones o atlas. El mayor incremento de la colección se produjo en 1913 con el traslado de los fondos del Gabinete Geográfico existente en la Primera Secretaría de Estado o Ministerio de Estado $^{3}$. Por esa misma época debió ingresar el legado López Garat de mapas manuscritos, con un número importante de cartografía náutica y la serie singular de los mapas de las Provincias de Marina, con notable información de los recursos forestales y humanos de cada una en las que quedó dividida Andalucía (Ayamonte, Sevilla, Sanlúcar de Barrameda, Motril y Almeria). Dentro de los fondos manuscritos hay que destacar las respuestas al cuestionario que envió Tomás López para lo que iba a ser el Diccionario Geográfico de España, que contienen numerosos planos, croquis y dibujos donde destaca el encuestado los elementos territoriales o los aspectos urbanos más significativos de su ciudad.

En la segunda mitad del siglo XIX nacen las instituciones civiles responsables de la cartografía nacional: Instituto Geográfico Nacional (1871), que realiza el Mapa Topográfico Nacional 1:50.000, y el Instituto Geológico y Minero de España (1848), que confecciona el Mapa Geológico de España 1:50.000. El Instituto Geográfico Nacional (IGN) debió realizar una ingente labor para elaborar el mapa nacional, levantando y nivelando toda España. En su archivo y biblioteca conserva toda esa información histórica que hoy constituye la de mayor cobertura histórica del territorio de la Comunidad Autónoma. Sus minutas, junto a las hojas del Mapa Nacional Topográfico Parcelario (obra del también IGN cuando se le asignaron funciones catastrales), son la cartografía más consultada y cuya información produce más satisfacción a los usuarios de la cartoteca con problemas de lindes, caminos o vías pecuarias.

\section{Las cartotecas militares}

El Centro Geográfico del Ejército, el Instituto de la Historia y Cultura Militar y el Museo Naval han aportado una cartografía fundamental para la historia de Andalucia. Hasta la creación del Instituto Geográfico, fueron las instituciones militares las responsables de la cartografía marítima y terrestre de España y de sus posesiones de ultramar. Hoy el Centro Geográfico produce la cartografía militar de España y el Instituto Hidrográfico de la Marina es el responsable de la cartografía náutica. El Centro Geográfico y el Instituto de Historia nacen cuando se crea el Estado Mayor en 1810, mientras que el Museo Naval hereda y custodia la documentación y la cartografía de la antigua Dirección de Trabajos Hidrográficos.

Joyas como la Carta de Juan de la Cosa (1500) se custodian en el Museo Naval, junto a la documentación original del Atlas Marítimo de España de Tofiño (1789) y las series de cartas náuticas publicadas por la Dirección de Hidrografía en la segunda mitad del XIX (dirigidas por el Capitán de Fragata José Montojo y Salcedo y su sucesor, el Capitán de Fragata José Gómez Imaz). El Centro Geográfico del Ejército tiene un volumen muy importante de mapas originales manuscritos y cartografía impresa, y es dificil seleccionar, posiblemente en la mejor cartoteca de España, una serie o un mapa 
para destacarlo entre los demás; basta mencionar la cartografía urbana que levanta el Estado Mayor de las ciudades andaluzas o la cartografia manuscrita e impresa de los trabajos del Coronel de Ingenieros Francisco Coello. El Centro Geográfico dispone de una importante colección de atlas e instrumentos de Topografía y Geodesia. Su cartoteca está catalogada hasta 1900 por lo que se espera un notable incremento cuando se incorpore la cartografía del siglo XX con interesantes piezas de la primera mitad de siglo.

Por último, el Ejército tiene en Sevilla el Museo de la Región Militar Sur, donde se han sumado a los antiguos fondos documentales de la Capitanía General los de las Comandancias de Obras de Andalucía. Por último mencionar que las bibliotecas de los gobiernos militares de Cádiz y Algeciras fueron catalogadas antes de ser trasladadas a Madrid.

\section{CONCLUSIÓN}

Los trabajos de la cartoteca se han extendido a algunas bibliotecas y archivos de Europa y América donde se han localizado y reproducido, entre otros, el Mapa de Napoleón (1811) (Bureau Topographique de l'Armée d'Espagnea. 1:100.000), la serie del Mapa Alemán (194044) (Spanien 1:50.000 Deutsche HeeresKarte), las series del Mapa Americano (1942-44) (Spain 1:50.000 Army Map Service: Series M781-M787) y el Mapa Americano 1:250.000 (1944-51) (Iberian Peninsula 1:250.000 AMS M581). A los que hay que añadir otros mapas que, si no son importantes en número, sí en singularidad y significado en la historia de la cartografía de Andalucia.

Desde el comienzo de los trabajos de recopilación de la cartografía se ha tenido una clara conciencia de la necesidad de preservar este tipo de documentación. En algunos casos se ha colaborado en la organización de los fondos cartográficos; en todos en los que se ha podido reproducir se ha dejado un original del microfilm o una copia digital y actualmente se facilita a los ayuntamientos que lo solicitan información y copia de los mapas del municipio para exponerlos o integrarlos en sus nuevos centros de documentación. El mal estado de conservación del primer plano urbano de Córdoba (Córdoba 1811, del ingeniero de minas Baron de Karvinski y el ingeniero de puentes y calzadas Joaquín Rillo) nos llevó a promover y sufragar su restauración. Las mismas circunstancias nos han hecho promover la restauración de la primera edición del Mapa Geológico de España y Portugal de Manuel Fernández de Castro (1889), cedido en depósito por un particular al Instituto de Cartografía de Andalucia, que actualmente se encuentra depositado en el Instituto Andaluz del Patrimonio de Andalucía para acometer su tratamiento.

La cartoteca continuará con su labor de localizar, reproducir y difundir la cartografía antigua de Andalucia que nos informe del pasado de nuestras ciudades, del territorio y del paisaje de Andalucia. Buscamos porque sabemos que podemos encontrar datos claves para entender su evolución histórica, pero ¿qué cartografía histórica le estamos dejando a nuestros sucesores?
Nuestra cartografía es cada vez más precisa, acorde con los nuevos sistemas de localización y posicionamiento, construida con un alto nivel tecnológico, con su información organizada en bases de datos que forman capas vectoriales susceptibles de ser tratadas y actualizadas individualmente. Sus datos están controlados desde su producción y descritos al mínimo detalle en los metadatos.

Su diseño y valores estéticos se dejan al gusto del consumidor como un acto individual, pero ¿han desaparecido los valores culturales y artísticos asociados al mapa dibujado o impreso en un soporte físico? ¿Se conservan cortes cronológicos de la cartografía que está sometida a una permanentemente actualización? ¿Serán las ortofotos las únicas que nos mostrarán cronológicamente cómo han evolucionado nuestras ciudades o el territorio de Andalucia? ¿Qué documentación gráfica custodiará nuestros archivos o contendrá nuestras cartotecas de los últimos quince o veinte años? Quizás las cartotecas del futuro no conservarán el romanticismo de las actuales pero siempre deberán de custodiar las "noticias antiguas del territorio".

\section{Notas}

${ }^{1}$ No obstante, la estampación calcográfica (hasta la primera mitad del s. XIX) obliga a retocar las planchas debido al desgaste que sufrian, dando lugar a distintos "estados", con diferencias que permiten identificar las distintas ediciones.

2 El primer catálogo de la biblioteca escrito en 1729 por el bibliotecario Juan de Iriarte está precisamente dedicado a los fondos cartográficos Regia Matritensis Biblioteca Geographica et Chronológica.

3 "Dentro del ambiente científico en que se desarrolló la actividad profesional de los marinos españoles en el siglo XVIII, destaca la personalidad del capitán de navío José Mendoza Ríos, al que se le encomendaron importantes tareas en el campo científico (...) En 1795, Manuel Godoy creó el Gabinete Geográfico de la Primera Secretaría de Estado, para centralizar y custodiar las colecciones de mapas, cartas náuticas, etc., y encargó su organización a los cartógrafos Tomás y Juan López, por su experiencia y eficacia, con la finalidad de "formar y cuidar una Colección general de mapas para el servicio de la propia Secretaria, debiendo procurar que fuese igual o semejante a las que, en Francia, Inglaterra y otras naciones, existen." (en http://www.bne.es/es/Actividades/ActosCulturales/CicloCitaBN/CitaBN2007/Mapas ColeccionMendoza.html).

\section{Bibliografía}

COLECCIÓN de Cartografía Histórica [cd-rom]. Granada: Biblioteca de Andalucia, Consejeria de Cultura, Junta de Andalucia, 1998

CONTRERAS GILA, S. (coord.) (2008) Catálogo de la Biblioteca del Instituto de Estudios Giennenses. Jaén: Diputación, Instituto de Estudios Giennenses, 2008 CONTRERAS GILA, S.; LÓPEZ CORDERO, J. A. (2008) Cartografía histórica giennense Siglos XVII-XX. Jaén: Diputación, Instituto de Estudios Giennenses, 2008 HARLEY, J. B. (2005) La nueva naturaleza de los mapas. Ensayos sobre la historia de la cartografía. México: Fondo de Cultura Económica, 2005 POSADA SIMEÓN, J. C.; PEÑALVER GÓMEZ, E. (coord.) (2010) Cartografía histórica en la Biblioteca de la Universidad de Sevilla. Sevilla: Universidad de Sevilla, Biblioteca Universitaria, 2010

RESTREPO BOTERO, G. M.; VElASCO ÁlVAREZ, A. C.; PRECIADO BUITRAGO,

J. C. (1999) Cartografía Social. Terra Nostra, Universidad Pedagógica y Tecnológica de Colombia, Especialización en Gestión de Proyectos, n. 5, 1999, pp. 5-39 ROMERO TALLAFIGO, M. (1994) Archivistica y archivos. Soportes, edificios y organización. Carmona (Sevilla): S \& C, ediciones / Asociación de archiveros de Andalucía, 1994 